\title{
The Path of Improving China Water Environment Through Green Infrastructures and Ecological Engineering Facilities
}

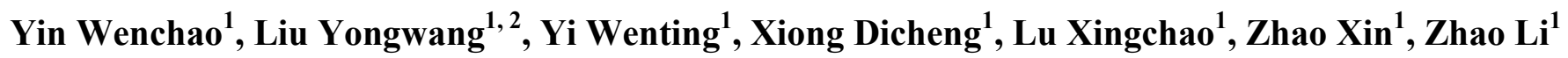 \\ ${ }^{1}$ Green Design Institute, China Architecture Design Group, Beijing, China \\ ${ }^{2}$ College of Environment and Energy Engineering, Beijing University of Technology, Beijing, China
}

\section{Email address:}

yinwc@cadg.cn (Yin Wenchao)

\section{To cite this article:}

Yin Wenchao, Liu Yongwang, Yi Wenting, Xiong Dicheng, Lu Xingchao, Zhao Xin, Zhao Li. The Path of Improving China Water Environment Through Green Infrastructures and Ecological Engineering Facilities. American Journal of Water Science and Engineering. Vol. 4, No. 3, 2018, pp. 50-65. doi: 10.11648/j.ajwse.20180403.11

Received: August 14, 2018; Accepted: September 10, 2018; Published: October 10, 2018

\begin{abstract}
In recent years, ecological progress has been promoted and given high priority by Chinese government. The improvement of urban water environment, as an important part of urban construction, should also be included in the ecological progress. This paper focuses on upgrading the quality of urban water environment in China. The study introduces the requirements of the ecological progress, and analyses the problems of water environment caused by urban development. A large number of research and case studies have been done to explore the paths, models and methods which improves urban water environment from both meso-scope and micro-scope. The analysis shows that urban water environment can be improved through three innovations-theoretical innovation, technological innovation and management mechanism innovation. The meso-scope model of ecological urban water system is proposed as a theoretical innovation. Technological innovations such as hybrid ecological pond, in-situ purification of contaminated water and low carbon treatment for the integrated drainage system have been confirmed to be effective on improving the water quality and environment. As the management and mechanism innovation, clear responsibility division of government, social organization and individuals and new business models are also useful. It is suggested that the innovations in three fields discussed above should be gradually decomposed and implemented at the micro level, so as to develop the path of urban water environment improvement, which suitable for China.
\end{abstract}

Keywords: Ecological Treatment, Hybrid Ecological Pond, In-situ Purification, Drainage System, Mechanism, Rainwater Management

\section{Introduction}

"Ecological improvement vitalizes civilization, and ecological degradation weakens civilization". Since the 18th National Congress of the Communist Party of China, ecological civilization construction has been placed on the strategic position of the "Five-in-one" general layout of national development.

Since the reform and opening up, China has experienced the fastest and largest urbanization in the world, which has brought tremendous achievements and also various urban diseases. In particular, urban water environment has become a universal problem for Chinese cities and seriously influenced people's livelihood and restrained the city development. According to the List of Black and Odorous Water in Urban
Constructed Land of China, there are black and odorous waters in over $70 \%$ of 295 cities, and the total amount achieves 1,861 . In view of this situation, improvement of urban water environment has surely been on the top agenda of the ecological civilization construction.

Being included in the "Five-in-one" general layout, ecological civilization construction theories have demonstrated the direction and values of national development. The Five Development Concepts are the pillars of the general layout. In urban construction, particularly the improvement of urban water environment, requires the establishment of implementation paths, models and method systems from the meso and micro scope, in order to implement and enrich the theories and practices of ecological civilization construction.

In this context, the rules of urban development should be re-explored and the realities of urban water environment should 
be reviewed and envisaged in China. The development of urban water systems should follow the green track, by taking the meso-scope theoretical innovations as the breakthrough to implement ecological civilization construction theories in cities and solving the micro-scope problems through the innovation of technologies and management mechanism.

\section{Respect Rules of Urban Development and Envisage the Water Environment Problems}

"Doing a good job of urban work must respect the rules of urban development", as the Central Urban Work Conference specified. Urban development is a process of natural history with its own rules. Development of city and economy supplement and promote each other. Development of city is the process of rural population concentrating into the city and agricultural land transferring to urban construction land according to the quota. In this process population scale and land resources must be properly planned and city size must adapt to the carrying capacity of resource environment. Moreover, the urban development rules should be respected and followed and the appropriate development guidelines should be defined while implementing urban work.

Agglomeration of production and population has promoted the city development, brought the unprecedented aggregation of productivity, and meanwhile produced tremendous material wealth. Despite the problems emerging during the industrialization and increase of population, it can never be denied that industrial society brings the highly developed cities, which is the inevitable result of socio-economic development, and also the manifestation of social progress.

City has different kinds of problems which should be faced squarely. And these problems also should be solved gently and gradually through continuous innovation of management and technologies, and improvement of urban construction level. In terms of urban water environment, the following rules and realities should be confronted.

\subsection{Huge Amount and High Concentration of Urban Water Consumption and Sewage Drainage}

According to China Urban-Rural Construction Statistics Yearbook of 2013, the National urban water consumption per capita is 127 ton, and water consumption per square kilometer is 112 ton, and annual discharge of urban sewage is 417 billion ton, and water discharge per capita is 101 ton, and water discharge per square kilometer is 89 ton. Water consumption and discharge per square kilometer and per capita of city is 7.0 and 2.5 times larger than the value of countryside. The figures show that the high-intensity and high-density multilateral exchanges as well as high-efficiency public services in cities have brought higher water consumption needs and more concentrated sewage discharge.

The prominent problem is the poor regionalization of water resources and regional deterioration of water ecology, such as surface water pollution, underground water pollution and depression cone.

\subsection{High Percent of Hardened Surface, Tremendous Rainwater Runoff Drainage and Severe Non-point Source Pollution}

According to the remote sensing analysis of the urban hardened surface in Beijing, the construction coverage in all gradient zones of the constructed land within the Fifth Ring Road is very high, particularly within the Fourth Ring Road. Moderate-density and high-density constructions occupy the absolute predominance in proportion. Heterogeneity of the landscape types dominates the overall landscape pattern of the constructed land in Beijing, represented by the high heterogeneity of patch size and shape[1].

A prominent reality is the comprehensive urban rainwater runoff coefficient is between 0.4 and 0.5 , even above 0.7 in some regions with high building density and plot ratio, such as old urban districts and CBD. These regions are faced with high drainage pressure and high risk of waterlogging, and the supply channels of urban underground water reduces drastically. In addition, severe non-point source pollution of surface water is another threat to the rainwater runoff.

\subsection{Unity and Opposition of Urban Water Functions and Ecology}

Urban waters include city rivers, lakes, reservoirs etc. which has different functions, such as providing drinking water, regulating flood, balancing ecology and beautifying the city. Functional orientation of an urban river determines its embankment type and improvement technology. It must be clarified that urban rivers should be integrated with urban functions. The improvement of river should be able to drive the integrated development of the city and promote the overall value of the city, and finally achieve the integration of river and city by satisfying both human needs and recovery of ecosystem.

In case of narrow riverway and high flow, it is necessary to use hard materials for the safety of embankment. For example, it is allowed to use the retaining wall or the retaining structure consisting of hard materials and ecological materials appropriately. Meanwhile, ecological compensation areas can be set up in proper sections, where broadening riverway properly, and applying ecological materials to build the embankment, in order to compensate the material and energy exchange in this section.

Retaining wall has outstanding advantages such as safe structure and occupation of fewer land. Ecological improvement of rivers is the ecological measures under the premise of ensuring the safety of flood control. Flood control is the basic function of river, and stability of embankment structure is the most important thing. Therefore, urban development rules require the coordination and unity of water functions and ecology within the cities.

\subsection{The Conflict Between Urban Development Progress and Backward Water System Construction}

The problems which between urban development progress 
and backward water system construction are the hard pavement reform of the old urban districts, the upgrade of drainage pipeline network and the installment of reuse water pipeline network in the old urban districts, the development of compacted soil greening and underground spaces in the old urban districts, rainwater and sewage collection and processing in urban renewal (drainage capacity and processing capacity).

The prominent problem is that in most old urban districts the combined sewer is applied, and moreover, the collection, processing and recycling of urban rainwater and sewage lags far behind the fast large-scale development of new urban districts. In addition to the separation of rainwater and sewage, and construction of centralized sewage treatment plant, the balance among society, economy and environment must be fully considered to figure out a new solution.

\subsection{Significance and Limitation of Urban Sewage Processing}

The activated sludge process has already greatly improved the carrying capacity of urban environment. However, total dependence on the improvement of treatment capacity is a serious challenge for the capability of city government, which is incapable of preventing the continuous degradation of urban water environment. It is imperative to apply the effect-oriented improvement and the integration of technologies, instead of depending on any single factor.

The problems and conflicts that the urban water system in China has encountered are inevitable in the process of urban development, thus we need to respect urban development rules, and face the problems seriously. Including the ecological civilization construction into the "Five-in-one" general layout is a top-level design theory from the long-term national development, meanwhile, innovation is considered as the top priority of the five development concepts to break the bottleneck in all development fields. In such a significant period of new normal development, all city managers, constructors and research staffs must take the ecological civilization construction as the guidance to innovate the improvement of urban water environment in China from the perspectives of theory, technology and management system.

\section{Develop an Innovative Path for the Urban Water Environment Improvement in China}

\subsection{Theoretical Innovation-Build the Ecology + Urban Water System Model}

It is imperative to figure out the mesoscopic way of implementing the ecological civilization construction theories in urban water system, guided by its requirements on urban construction and improvement of water system.

"Ecology + urban water system" is a new construction and renewal model for urban water system under the guidance of ecological civilization construction theories, which respects urban development rules, national conditions, current situation and trend of city development. The core task is to build a mesoscopic model and method system framework of ecological civilization construction theories in the urban water system construction. "Ecology +" in this context refers to the following three patterns.

(1) Ecology + temporal-spatial limitation (time, space, city and city development level);

(2) Ecology + functional needs (economy, society, culture, and living);

(3) Ecology + innovation spirits (technological innovation, management innovation and system mechanism innovation).

By combining with the above-mentioned problems of water system brought by city development, the "ecology +" patterns will be further explored with a few examples.

\subsubsection{Ecology + Temporal-Spatial Limitation}

In view of these temporal-spatial problems, such as high degree of hard surfaces, great rainwater runoff, difficulty of reforming sewage pipeline network in constructed land and installing the reuse water pipeline network, poor capacity of collecting and processing rainwater and wastewater during the rapid urbanization, it is improper to blindly copy the measures that foreign countries have successfully applied, and actual conditions of local areas must be considered to make the best use of their advantages.

For example, the rainwater runoff control should be coordinated with the comprehensive improvement of the environment in old residential districts; the utilization of reuse water in constructed area should adopt both concentrated and separate models to avoid the energy consumption for long-distance sewage collection and reuse; the conflict between rapid urbanization and poor capacity of collecting and disposing sewage can be solved by building aerobic ponds in parks and green lands, and using the in-situ purification technology of wetland and river.

\subsubsection{Ecology + Functional Needs}

Comprehensive improvement of urban river environment in the emerging construction of spongy city and the control of black and odorous water can be taken, for example, learning the successful experience from South Korea and Singapore in improving the rivers such as the Qingxi River, Guangzhou River and Singapore River. It must be clarified that city rivers should be integrated with city functions, and the river improvement should be able to drive the comprehensive development of the city, and improve the overall value of the city. The improvement should make the city and rivers into an organic whole, satisfy the needs of mankind and recover the ecosystem.

\subsubsection{Ecology + Spirit of Innovation}

Innovation is a kind of activity that proposes the concepts different from the conventional methods based on the existing thinking mode, and uses the acquired knowledge and materials to improve or create new things, methods, elements, paths or environment in a specific situation for the idealization or meeting particular social needs, somehow achieves beneficial effect. 
The concept of innovation includes both temporal-spatial limitation (acquired knowledge and material, specific situation) and functional needs (idealization or social needs), and also gives the object and result of innovation (things, methods, elements, paths and environment), as well as the ultimate goal (beneficial effect).

"Ecology + spirit of innovation" indicates the active theoretical, technological, management and system innovation in exploring the ways of improving urban water system in China.

Taking technological innovation as an example, it is urgent to develop a new way of sewage processing and water environment improvement, which considering temporal-spatial needs such as land use and practicability, as well as functional needs such as safety and beauty, and developing the low-carbon and ecological treatment technologies and processes.

\subsection{Technological Innovation}

\subsubsection{Problems in Technological Development}

The present concepts in terms of sewage processing and water environment improvement lag far behind the spirit of "comprehensively deepen the reform" proposed by the Third Plenary Session of the $18^{\text {th }}$ CPC Central Committee, particularly the spirit of ecological civilization construction. There is even a bigger gap between the present concepts and the "creative, coordinated, green, open and shared" development concept supported by the spirit of the $18^{\text {th }}$ National Congress of CPC, and the Third, Fourth and Fifth Plenary Session of the $18^{\text {th }}$ CPC Central Committee. And the gap lies in the following aspects.

(1) Sewage processing focuses more on the activated sludge process and new technologies, but less on other practical processing technologies. For example, stabilization pond, artificial wetland and land processing technology is suitable for middle and small scale cities and countryside, which mostly applied in middle and small scale communities and countryside of developed countries.

(2) Processing and utilization of sludge is totally neglected. The sludge in all sewage plants of the U.S.A. is called "Biosolid", and widely used as the organic fertilizer for farmland, orchard and forest after dehydration and drying, or as soil conditioner for green land and golf course. The biggest challenge for sewage plants in China is the non-hazardous treatment decreasing and recycling of the sludge processing and disposal.

(3) Collection, conveying, processing, non-hazardous treatment and recycling of urban rain runoff has been neglected. Hence the cities have been flooded in case of heavy rain, which has never been efficiently handled. Germany has made the world's best example in rainwater collection, processing, regeneration and use of single household, block, city and even basin. Both of its combined system and separate system has achieved remarkable results in the non-hazardous treatment and resource utilization of rainwater.

\subsubsection{Suggestions for Technological Innovation}

The thought and concept urgently needs to be refreshed with the guidance of the spirit of the Fifth Plenary Session of the 18th CPC Central Committee. And advanced technologies and experience should be borrowed from other countries and combined with actual conditions of China. "Borrow" in this context does not mean "blindly copy". we have to figure out A new low-carbon and ecological road which is for rainwater and sewage processing and water environment treatment has to be figured out with pioneering and creative spirits. And the suggestions go from the following aspects.

$i$ Eco-processing of rainwater and sewage: the combination of function and beauty.

a. Eco-pond rainwater and sewage processing technologies and application in Germany.

In the improvement project of River Ruhr, the facilities are installed in the whole basin, including the sewage plant with concentrated oxidation ponds, riverfront wetland purification along the river and a great amount of separate sewage processing facilities such as stabilization ponds, oxidation ponds and bio-ponds in small cities and countryside. Among the sewage plants of the River Ruhr Association, $40 \%$ of them choose final purification pond (multi-stage pond) as its tertiary processing to produce high-quality effluent (for example SS and $\mathrm{BOD} \leq 10 \mathrm{mg} / \mathrm{L}$, amount of bacteria and coliform decreases $>99.999 \%$ ), which compared with chlorination eliminates the generation of excessive organic halide and water source pollution, and is more economical, safe and beautiful.

In addition, rainwater runoff is collected, processed, purified and used as an important water resource. There are 549 rainwater runoff facilities designed, built and in operation (statistics of 2009), and major processing facilities include rainwater sedimentation pond, rainwater purification pond, surface runoff artificial wetland etc., showing the ecological beauty of rainwater and sewage processing.

b. Origination of rainwater and sewage ecological improvement in China and application of the multi-stage strengthened compound eco-pond technology.

In terms of utilization of urban sewage and rainwater, Chinese ancestors have left precious technologies and experience. For example, the combined rainwater and sewage system in Ganzhou City built around 900 years ago, which including pipeline, rainfall flood storage and regulation, sewage and rainwater purification and processing system; the over 2000-year-old ecological circulation systems in the Pearl River Delta, such as mulberry fish pond, sugarcane fish pond and rice fish pond. These scientific and reasonable concepts are the final choices for modern people after long-term searching and trying. Since the 1970s, China has applied the sewage processing eco-pond and ecosystem (combined pond and artificial wetland, and artificial irrigation etc.), and successfully built the high-efficiency strengthened eco-pond. Eight projects have been put in operation nationwide, including. 


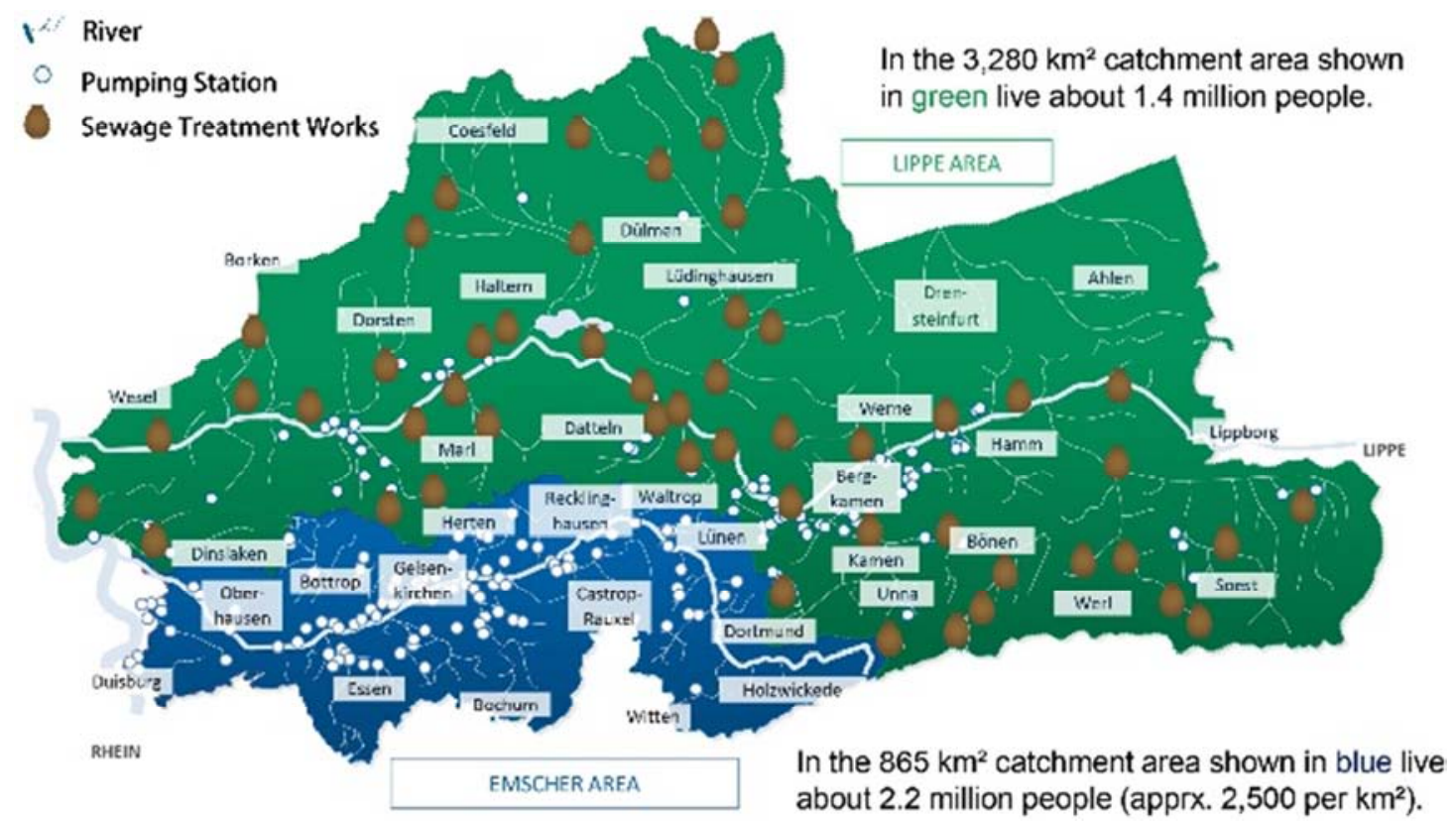

Figure 1. Distribution of water treatment facilities in the basin of River Ruhr.

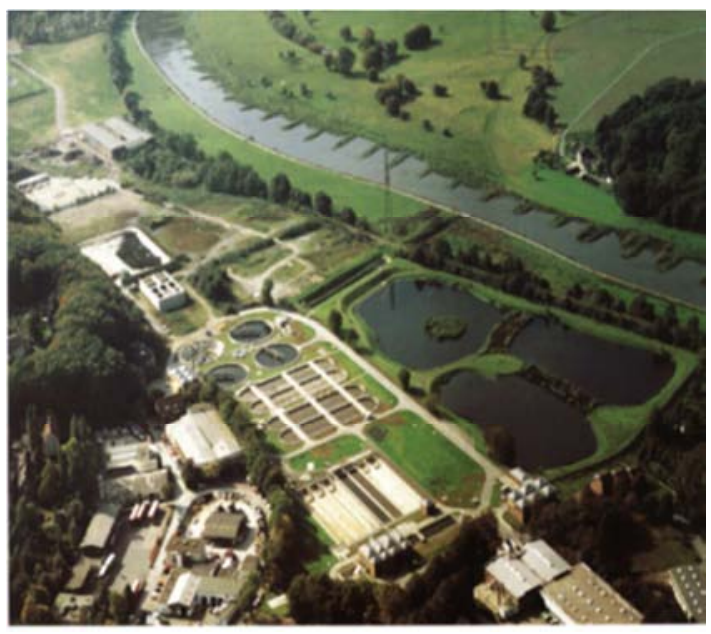

Figure 2. Three-stage purification pond in the sewage plant.

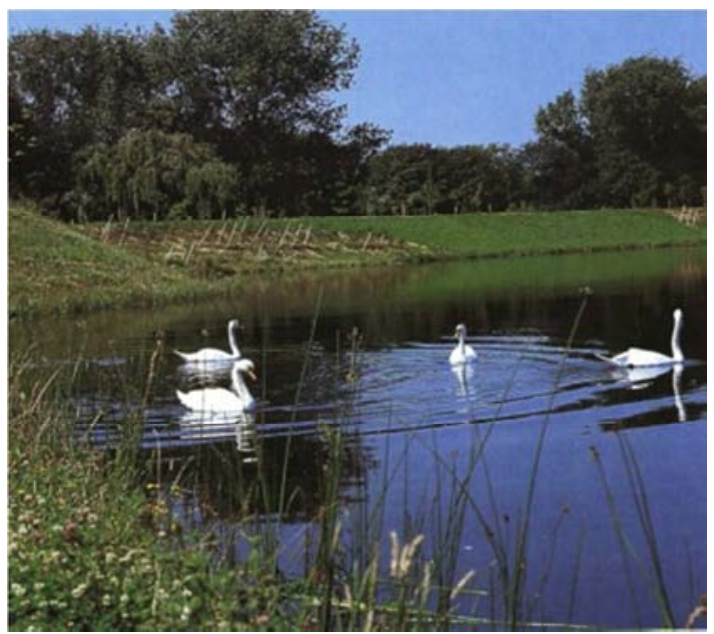

Figure 3. Rainwater purification pond.
(1) petrochemical wastewater eco-processing system in Daqing Petrochemical Corporation (Figure 4)

(2) multi-stage pond and wetland sewage eco-processing system in Dongying City, Shandong Province (Figure 5)

(3) sewage processing and utilization ecosystem of the Zihe River (Figure 6)

(4) the high-efficiency combined eco-pond system in Yingtan City, Jiangxi Province (Figure 7-9)

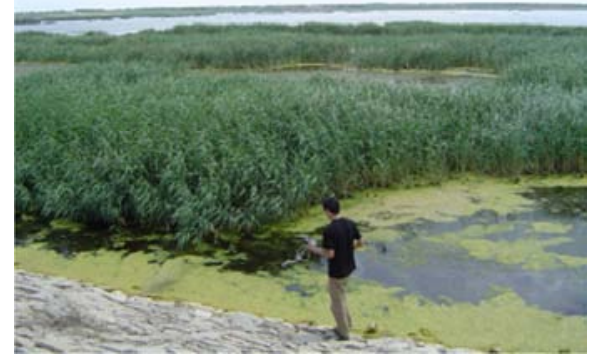

Figure 4. Wastewater purification pond in Daqing Petrochemical Corporation.

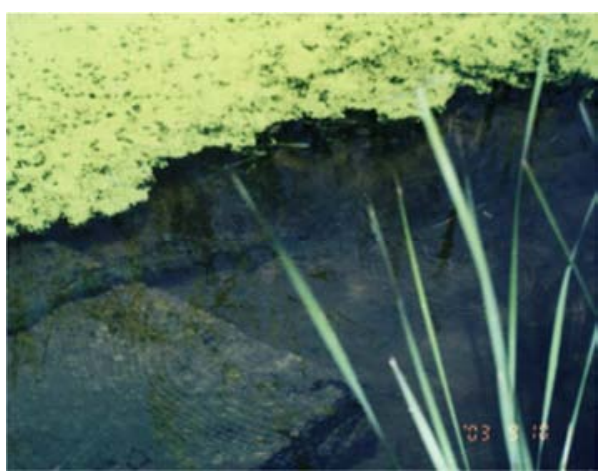

Figure 5. Reed wetland pond in Dongying. 


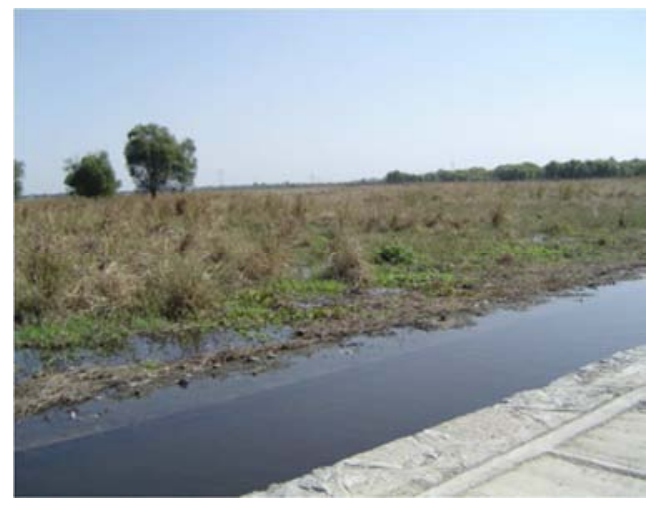

Taking the sewage plant in Yingtan City as an example, its multi-stage strengthened hybrid pond system can process the sewage to the effluent of Grade-I A standard. It has been in full operation for years and not produced any sludge for 3 continuous years. This multi-stage system includes pre-processing facilities (grid-aeration sedimentation pond), strengthened hybrid anerobic-facultative pond, hybrid aeration pond, sedimentation pond--hybrid purification pond (Figure 7).

Figure 6. Sewage eco-processing system of the Zihe River.

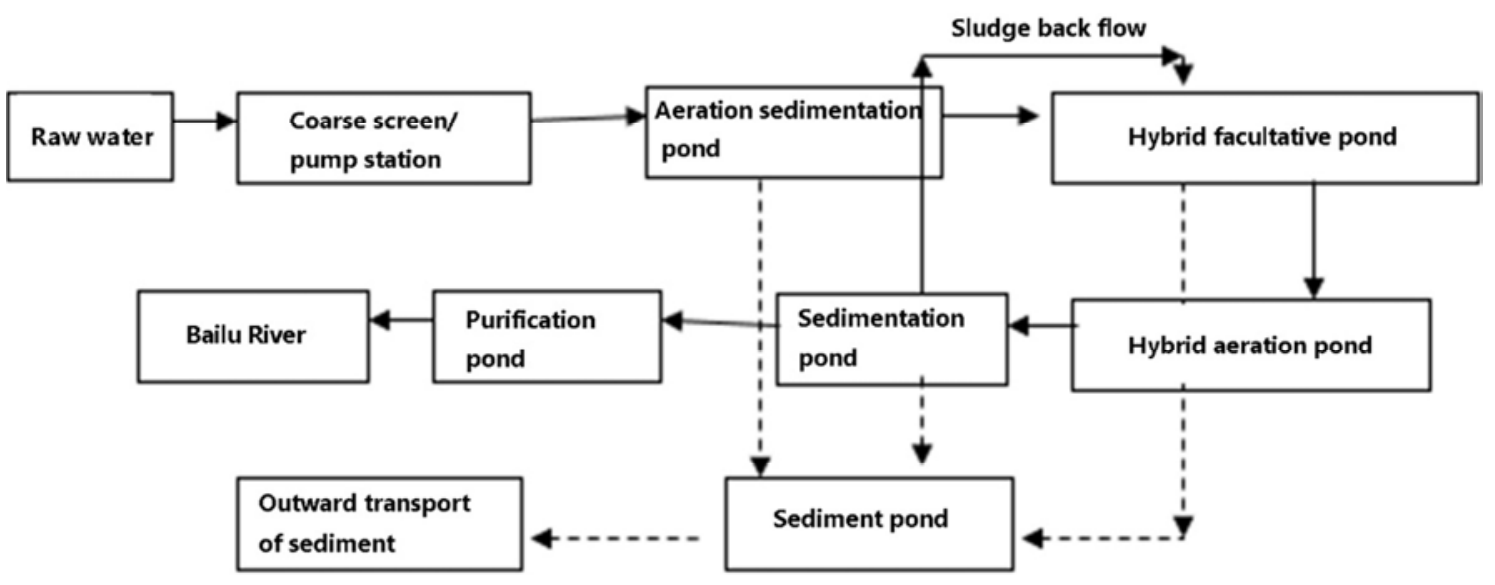

Figure 7. The high-efficiency compound eco-pond flow of the Yingtan Urban Sewage Plant in Jiangxi.

The operation of this multi-stage strengthened hybrid eco-pond proves the following aspects.

(1) The hybrid anerobic pond consisting of high-efficiency pre-processing facilities and biofilm carrier packing with high specific surface area (Figure 8 and 9), together with hybrid facultative pond, sedimentation pond and hybrid purification pond, has much larger biomass than the common pond system. Its biomass achieves $20-50 \mathrm{~g} / \mathrm{L}$ as the inflow COD $>300 \mathrm{mg} / \mathrm{L}$ and $\mathrm{BOD}_{5}>120 \mathrm{mg} / \mathrm{L}$. And the hybrid system has more biotic populations (biodiversity) forming longer and more food chains.

(2) The hybrid pond is highly efficient in processing domestic sewage, and sewage retains in the pond only for 3 days, which is much shorter than the conventional duration that a stable pond system needs (20-30 days).

(3) The hybrid pond shows a good and stable performance. The annual mean concentration of $\mathrm{COD}, \mathrm{BOD}_{5}$, $\mathrm{NH}_{4}{ }^{+}-\mathrm{N}$ and TP in the effluent is $31.37 \mathrm{mg} / \mathrm{L}, 6.72 \mathrm{mg} / \mathrm{L}$, $6.4 \mathrm{mg} / \mathrm{L}$ and $0.435 \mathrm{mg} / \mathrm{L}$. Water quality of the effluent is higher than Grade 1A all the year round. Some indexes such as COD and $\mathrm{BOD}_{5}$ achieves the standard $\mathrm{V}$.

(4) The hybrid pond consumes less energy, its specific energy consumption is $0.05 \mathrm{kWh} / \mathrm{m}^{3}$ in processing sewage; the annual mean direct operation fee is lower than 0.1 yuan $/ \mathrm{t}$ in processing sewage.

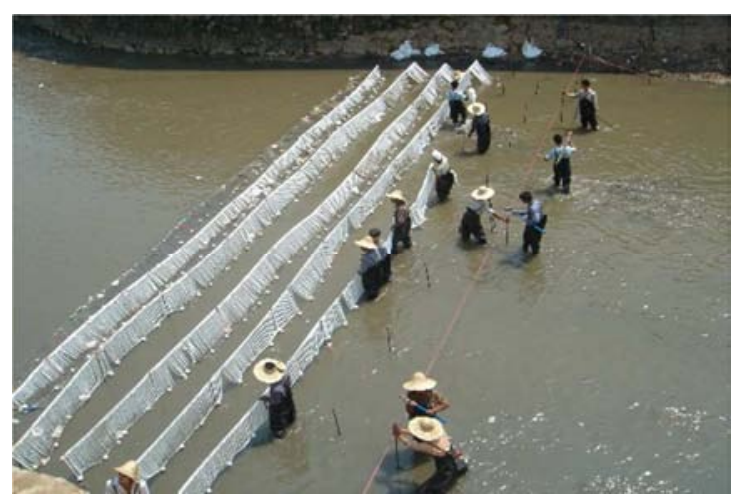

Figure 8. Installation of braided shade soft filler in river.

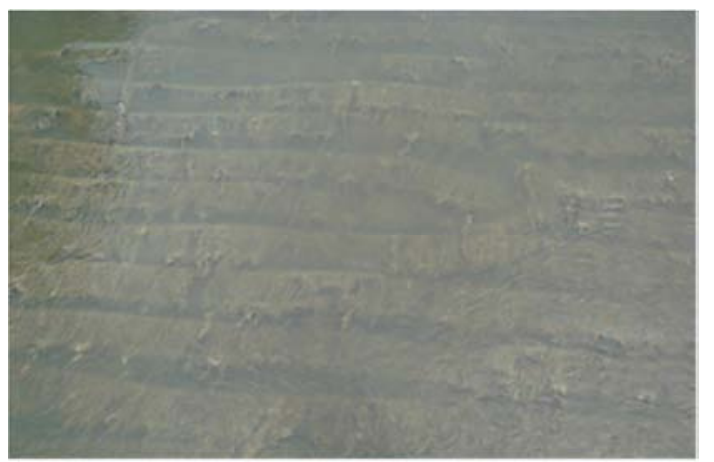

Figure 9. Biofilm growing luxuriantly on the braided shade filler. 
(1) Using the anerobic pond and the sludge fermentation pit at the bottom, the sediment sludge produces VFA, amino acid, soluble inorganic nutritive salt and gas such as $\mathrm{CH}_{4}, \mathrm{CO}_{2}, \mathrm{~N}_{2}, \mathrm{H}_{2}$, through hydrolysis, acidification and methane fermentation. Hence solid sludge has been reduced by transforming it into liquid and gas. As a result, the system has never discharged any sludge for 3 years, thus it is the zero-sludge-discharge sewage processing technology.

(2) The ecological compound pond system removes COD (BOD) and $\mathrm{CO}_{2}$. The final product $\mathrm{CO}_{2}$ from the bio-degradation of organism is absorbed by participating in the photosynthesis of algae and other aquatic plants in the pond, and releases the nascent oxygen. Therefore, it is a typical low-carbon sewage treatment technology.

(3) The proliferation of aquatic plants such as algae provide food for zooplankton, benthonic animal and fish, promoting the growth of these animals and formatting many food chains. Nutrients such as $\mathrm{C}, \mathrm{N}$ and $\mathrm{P}$ participate in the synthesis of these living organisms and are transferred into products and resources.

In total, the hybrid eco-pond system is an economic, energy-saving, recycling and low-carbon sewage processing technology, more suitable for middle and small scale cities and countryside.

a Small-scale sewage ecological processing technology and application in the U.S.A.

LMS company used the Living Machine Systems (LMS), i.e. the high-load and high-efficiency secondary artificial wetland system, in processing sewage of Port Authority Building in Portland (large-scale public building). The effluent after refined filtration, UV and chlorination achieved the quality standard of reuse water, and was used for toilet flushing and green land irrigation. Moreover, the ornamental plants in the artificial wetland were also the decorations for the building. In this way architectural aesthetics was perfectly combined with landscape aesthetics.

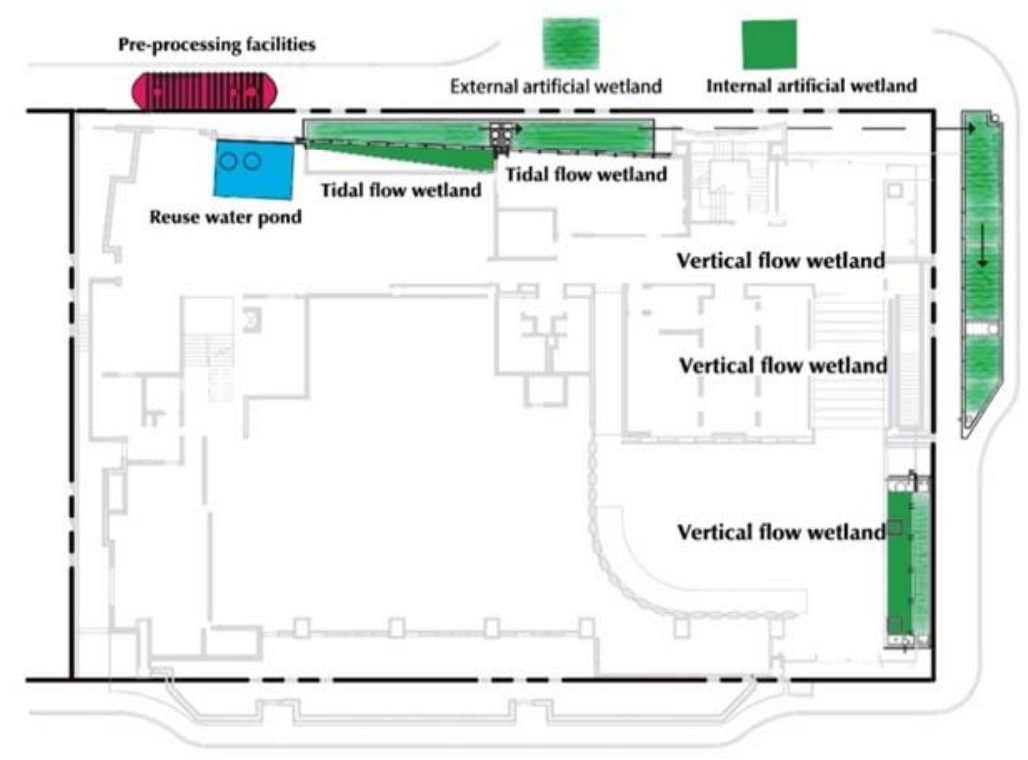

Figure 10. Layout of the internal and external wetland of the Port Authority Building in Portland.
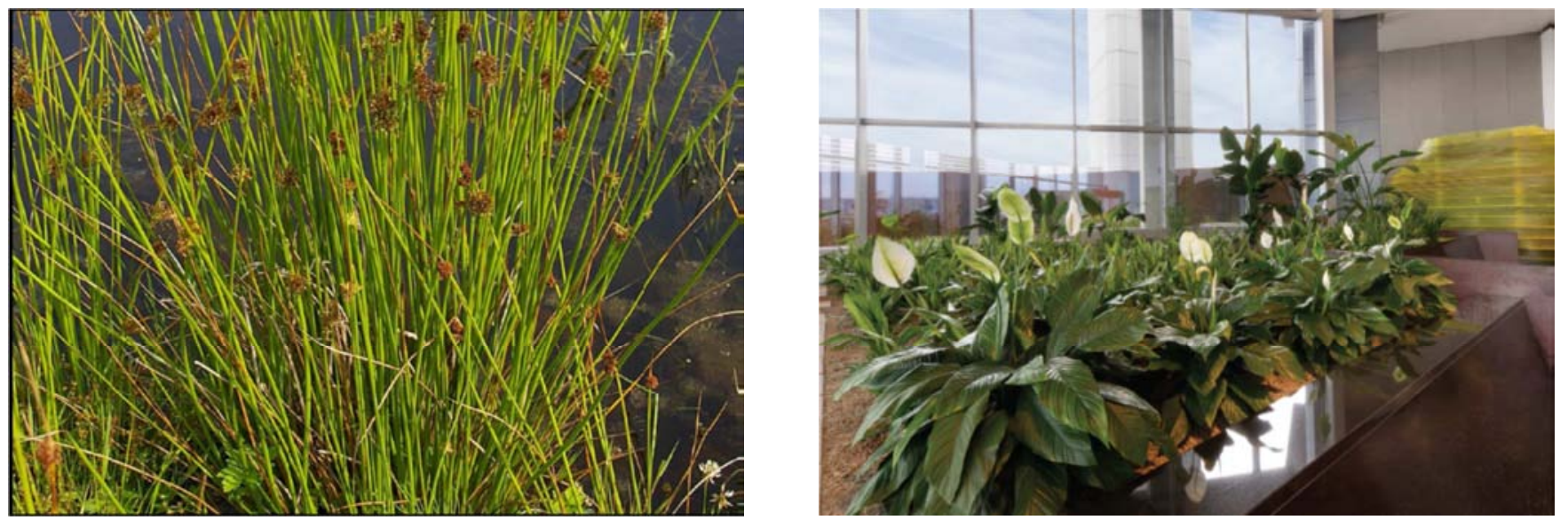

Figure 11. Photo of the internal and external wetland of the Port Authority Building in Portland. 
ii The "concentrated + separate" model of rainwater and sewage processing.

The concentration and separation of urban sewage processing has always been the focus of controversy in scientific research and engineering field.

Hermann Hahn once pointed out that the concentrated sewage processing system needed a long construction period, had higher requirements on the sewage collection pipelines, and required a huge investment. Moreover, many large-scale sewage plants are built in the lower reaches of the urban water systems, which holds back the regeneration and reuse of sewage. On the contrary, the separate sewage processing system realizes the in-situ reuse of sewage, which contributes to the benign regional water circulation in the city [2]. According to ICF Water and Sustainability Report 2002, 4\% of the annual power consumption in the U.S.A. was used for the operation of water and sewage facilities, among which the power consumption for water and sewage conveying is 4 times of that for processing [3]. As the advantage of separate sewage processing and reuse is realized, more and more commercial projects choose to install water reuse system in the U.S.A..

Sewage processing and reuse in China should also consider economic, social and environmental factors. The reuse water utilization-oriented "concentrated + separate" model can be applied for the sewage processing, which generally includes 3 following conditions considering the scale. (a) For agricultural irrigation and supplement of urban landscape water, it is proper to choose concentrated processing because of the tremendous amount and concentrated water consuming points; (b) For the use of industrial production, it is proper to combine concentrated and separate model. According to different industry types, sewage processing technologies can be chosen separately and then reprocessed after being concentrated in the industrial park, and again reused for different enterprises in the industrial park; (c) For single buildings, residential districts or parks, it is proper to choose separate sewage processing and reuse because of the small water consumption and the separate location of each water use point. The separate system could reduce the pipeline construction and the conveying of sewage and reuse water.

iii The in-situ integrated eco-purification technology of the contaminated water.

Despite the construction of sewage interception system and sewage plant, some sewage flows into the river because of the incomplete interception ratio. In addition, river water is contaminated by not only the sewage, but also all rainwater runoff. Moreover, the pollution concentration of urban rainwater runoff in China is much higher than that in foreign countries. As result, urban rivers have often high pollution load, generally belonging to the inferior Grade V. The reform and improvement of drainage system takes a great amount of investment and advanced engineering technologies, which cannot be accomplished within a short period, thus it is urgent to apply the in-situ processing and purification of the contaminated rivers and lakes in the city. The in-situ biotechnologies for contaminated river treatment include paving EcoRocks in the river, applying the soft fillers, planting various aquatic plants in the shallow water, applying more aeration and reaeration facilities and other artificial biological enhancement measures.

Taking the comprehensive treatment of Futian River as an example, the pollution of Futian River was treated with the Waterspur process, which achieved remarkable results. Water quality of the 3 river sections after regional treatment met the design requirements, and was close to the index of Grade $\mathrm{IV}-\mathrm{V}$ in the environmental quality standard of surface water.

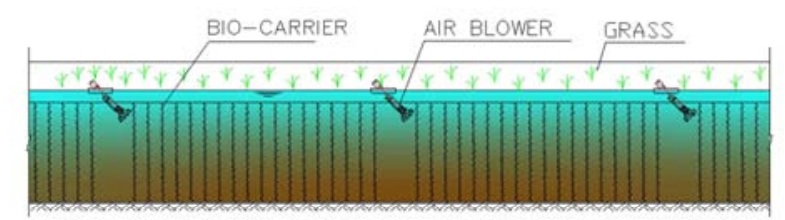

$\underline{B-B}$

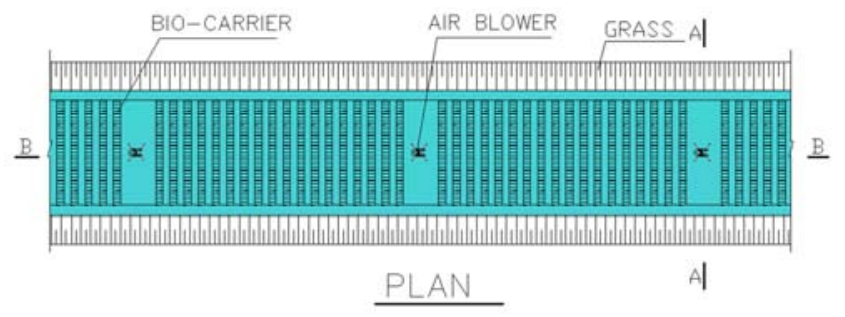

Figure 12. Layout of river purification facilities.

Waterspur process of the contaminated river is shown in Figure12-15.

(1) Build barrages or flap gate at the end of purified river to ensure the overflow on the top and form water with a certain depth.

(2) Fill with the soft biofilm fillers.

(3) Install the aerator (oxygen supply equipment).

(4) Add the specific bacteria to make them grow on the filler surface

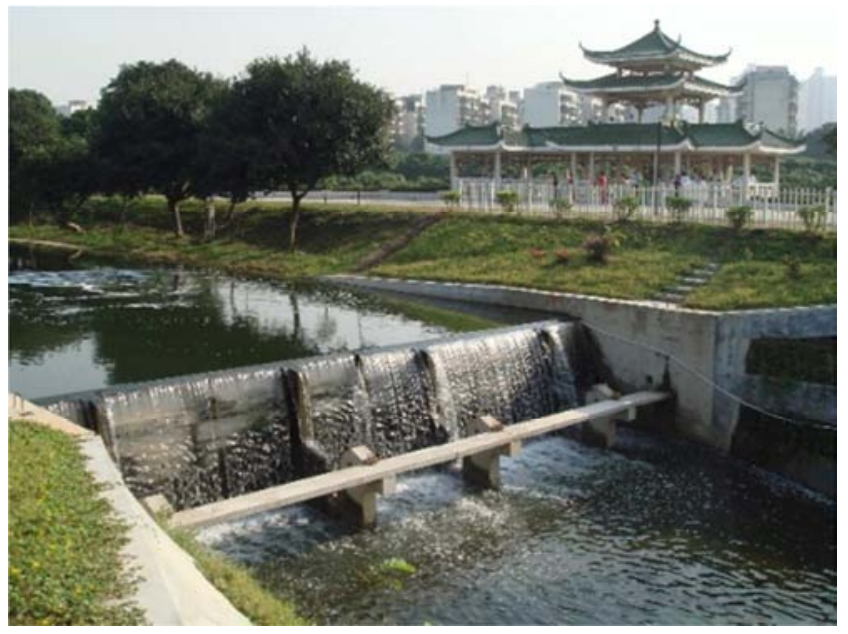

Figure 13. In-situ purification project of the Futian River Central Park.

After the 2-week operation of the purification project in the Futian River Central Park, the river water became clearer obviously, and a large amount of wild carps appeared in this 
section 2 months later. On this basis, the long food chain of bacteria, algae, protozoa, metazoan and wild fish is formed, which purifies river water efficiently and reduces sludge greatly. Main indexes of this purified river section $(300 \mathrm{~m})$ and the section at the lower reaches $500 \mathrm{~m}$ away achieved surface water grade IV-V.

The main sections of Futian river is located in parks. Based on the above-mentioned emergence treatment project, the accumulated experience and the location of the river, there are enough open space to transform this section of river channel into gentle slope and beautify the landscape with good ecological vegetation.

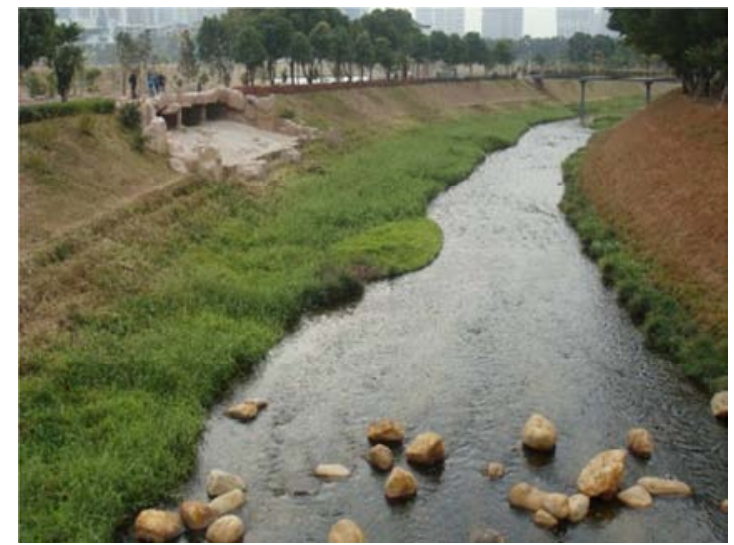

Figure 14. Rainwater overflow weir of the Futian River after ecological treatment.

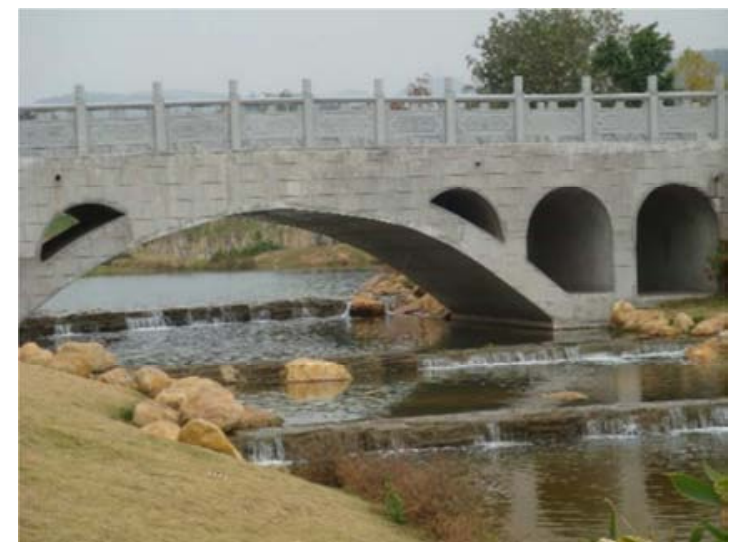

Figure 15. Multi-stage waterfall and aeration landscape under the bridge.

iv Introduce water ecological purification system into rivers in urban parks.

To guarantee water quality of the city, it is suggested that the urban park green spaces should be used to further purify the water on the basis of in-situ comprehensive purification. Specifically, sluice gate can be installed in the front of larger parks, green spaces and open spaces to raise water level, so that the water can enter into the pond-wetland eco-processing system built in the parks, green spaces and open spaces by gravity. Through multiple food chain ecosystems, the polluted river water is purified and then discharged into the main river channel.

This measure was adopted in the comprehensive treatment of urban river environment in Jiaozhou City to reform the
West Lake Park and Shuizhai green space. In the lakefront green spaces of the Xihu Lake Park, integrated flow wetland was designed. It is covered with filter bed composed of gravels, coarse sands and medium sands, in which water-loving plants such as Canna indica L., Phragmites australis, Scirpoides holoschoenus, and bamboos were planted. The hydraulic loading for the purification of less-contaminated water in such a wetland could be counted as $\mathrm{q}=2 \mathrm{~m}^{3} /\left(\mathrm{m}^{2} \cdot \mathrm{d}\right)$, thus the processing capacity of a $10000 \mathrm{~m}^{2}$ integrated flow wetland was $20000 \mathrm{~m}^{3} /$ d, i.e. it was able to deeply purify $1 / 3$ of the $6000 \mathrm{~m}^{3} / \mathrm{d}$ supplemental water for the lake.

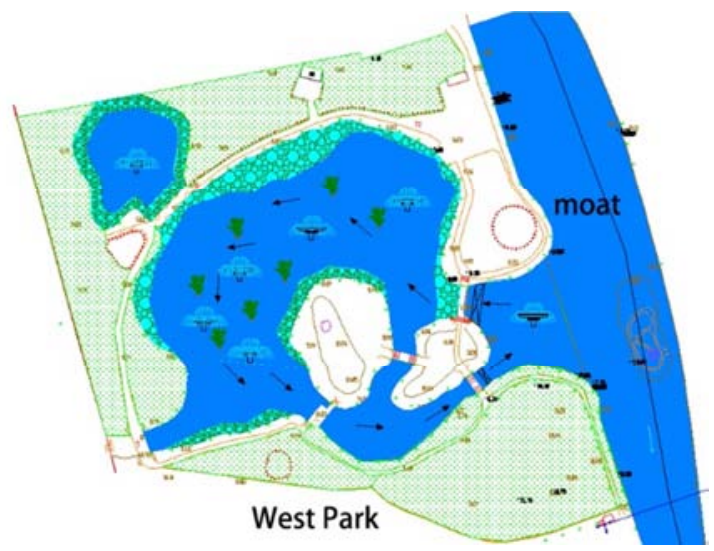

Figure 16. Concept map of the supplemental water purification project for the lake.
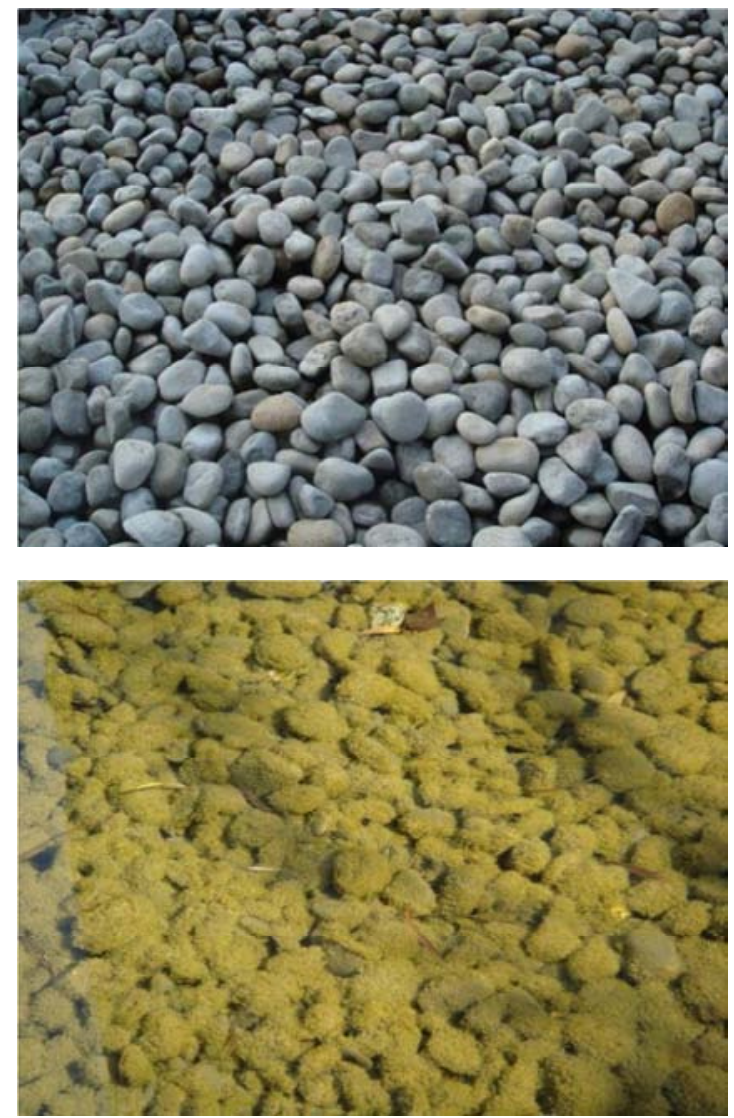

Figure 17. Primary pebble (left) and eco-stone formed after water purification operation (right). 


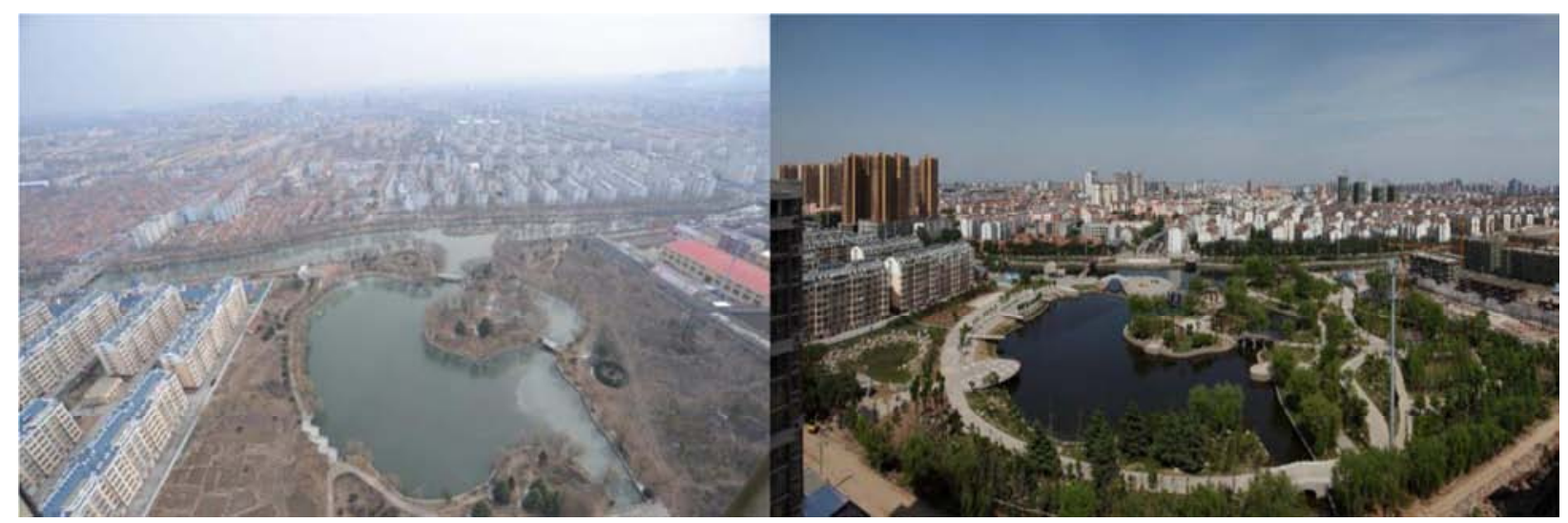

Figure 18. Panoramic view of West Lake before (left) and after (right) transformation.

Located in the lower reaches of the moat, Shuizhai green space was a landscape lake park for lotus planting. However, the trend of eutrophication had appeared due to shallow and stagnant water in the pond. In the front of the pond, a floodgate was built in the moat to raise water level, so that the water of moat flowed into the lotus pond by gravity. The water was purified during the flow and finally flow into the lower reaches. The totals surface of the pond is $5200 \mathrm{~m}^{2}$, and its total volume is $15600 \mathrm{~m}^{3}$ (mean water depth counted as $3 \mathrm{~m}$ ). Assuming the river inflow is $\mathrm{Q}=30000 \mathrm{~m} 3 / \mathrm{d}$, the hydraulic retention time (HRT) in the pond is $12 \mathrm{~h}$. If the inflow water quality belongs to grade $\mathrm{V}$, its main indexes will achieve surface water environment grade IV after the above-mentioned purification facilities.

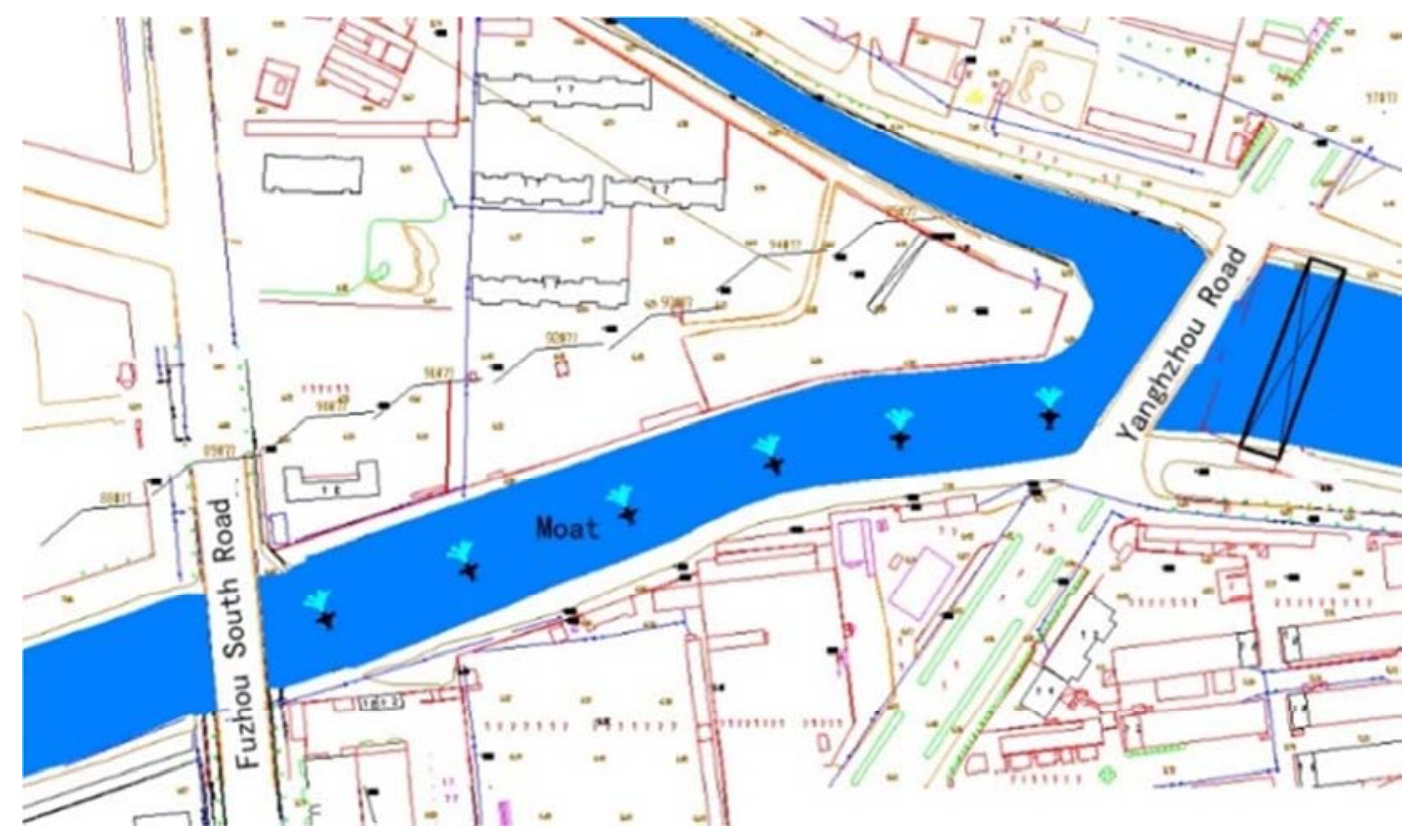

Figure 19. Layout of the purification section formed by the flap gate constructed at the end of the moat.
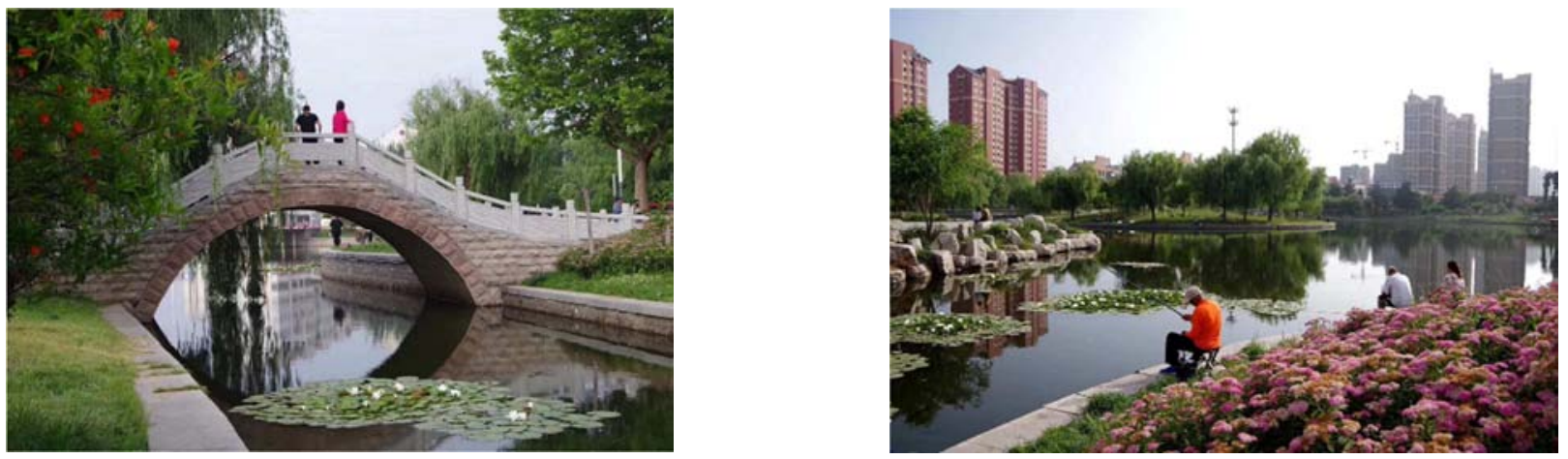

Figure 20. Picture of Shuizhai green space after renovation. 
As the main role of "precipitation and purification lake" is to precipitate suspended matter (including algae, bacteria, organic suspended matter, suspended clay particles, etc.) flowing through the river and to biodegrade, assimilate and transform the organic and nutritional pollutants. During the rainy season, the precipitation and bio-ecological purification of rainwater runoff are mainly carried out by "precipitation and purification lake". And the huge amount of sediment of suspended pollutants should be removed once or twice a year. In addition, interceptors should be set at the end of "precipitation and purification lake" to intercept and remove the floating garbage, leaves and branches carried by rainwater runoff. For jiaozhou city and almost all cities in China without special facilities for rainwater runoff treatment, it is extremely necessary to build precipitation and purification section at the wide part of the river. In fact, precipitation and purification of rainwater runoff is carried out and completed in such a wide river section. It plays an important role in protecting the lower reaches of Yunxi River and the Saohai lake.

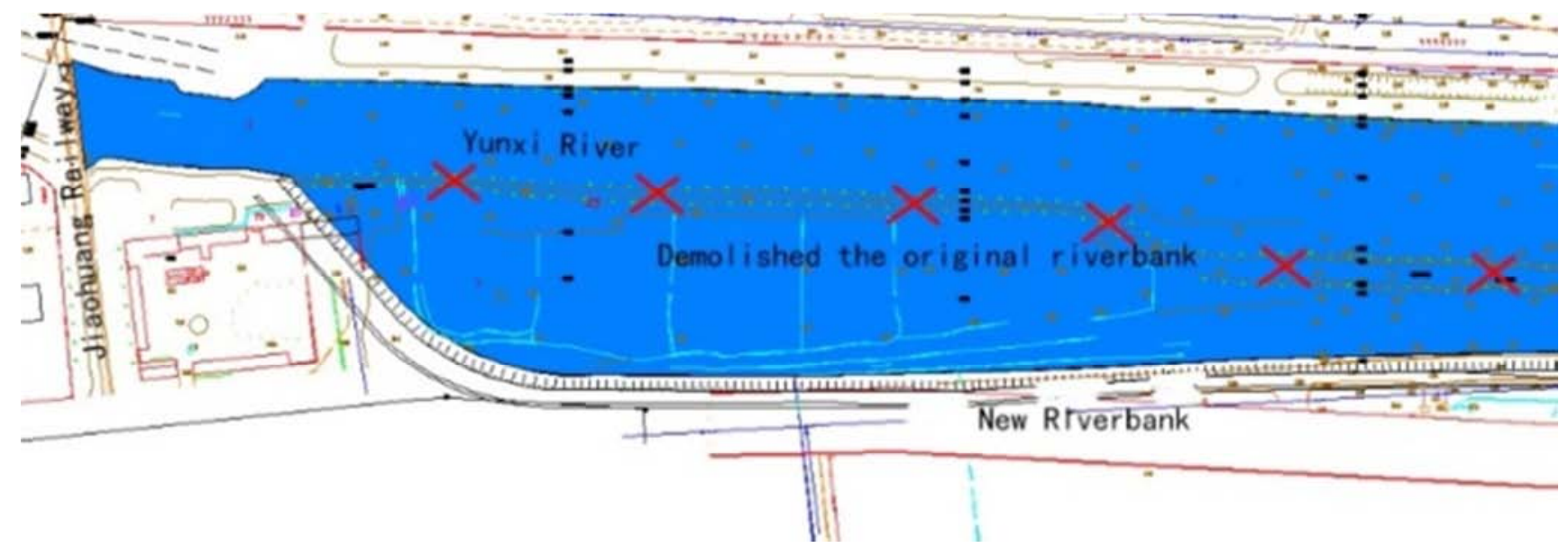

Figure 21. Layout of "sediment and purification lake" in the widening of the east section of Quanzhou road and Jiaohuang railway in Yunxi river.
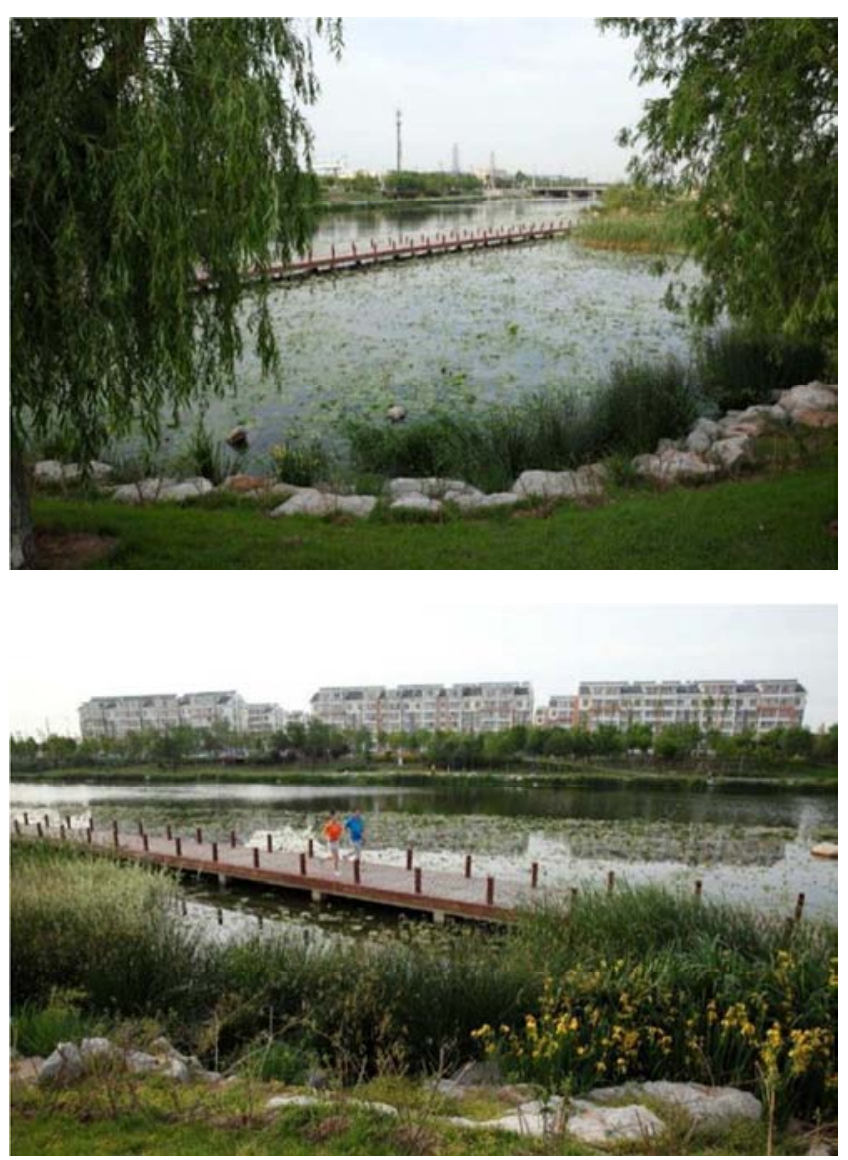

Figure 22. Pictures of "precipitation and purification lake" in Yunxi river.
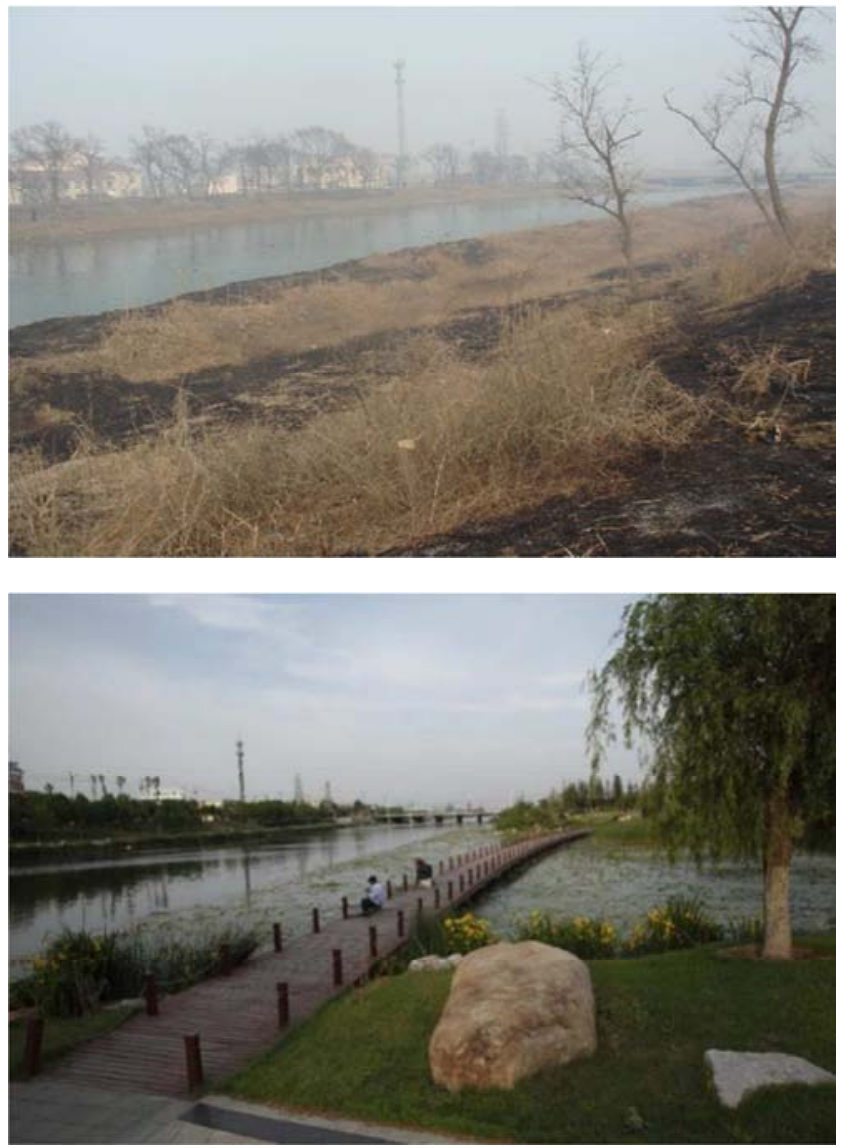

Figure 23. Pictures of the lower reaches of Yunxi river before (left) and after (right) transformation. 
The length of "precipitation and purification lake" is $1434 \mathrm{~m}$. The average width is $150 \mathrm{~m}$, and the average water depth is $3 \mathrm{~m}$. The cross water area is $\mathrm{F}=150 \times 3=450 \mathrm{~m}^{2}$. According to overwater velocity $\mathrm{v}=0.02 \mathrm{~m} / \mathrm{s}$ (the precipitation velocity of fine suspended particles is also the design velocity of the sedimentation tank), the overwater flow is calculated as follows: $\mathrm{Q}=450 \times 0.1=9 \mathrm{~m} 3 / \mathrm{s}$, or $32400 \mathrm{~m}^{3} / \mathrm{h}$, or $777600 \mathrm{~m}^{3} / \mathrm{d}$, and the rainwater runoff of $778,000 \mathrm{~m}^{3}$ (now $800,000 \mathrm{~m} 3$ ) per day. The "precipitation and purification lake" can be precipitated to remove $70 \% \sim 80 \%$ of suspended particles as in the sedimentation tank. Even if the "precipitation and purification lake" receives 1 million $\mathrm{m}^{3} / \mathrm{d}$ of rainwater runoff at the velocity $\mathrm{v}=0.026 \mathrm{~m} / \mathrm{s}$, it can still remove most of the sediment in the rainwater runoff. At this time, the hydraulic retention time (HRT) of the "precipitation and purification lake" was 19.92h, almost 20 hours. This is much larger than normal storm water sedimentation tanks and is much more efficient. Therefore, the "precipitation and purification lake" widened in the river plays an extremely important role in precipitation and purification of rainwater runoff, especially for the storm water pipe system directly discharging rainwater runoff into the river channel without treatment facilities. The rain water runoff "precipitation and purification lake" is indispensable.

$\mathrm{v}$ Low-carbon solution for the integrated drainage system.

As soon as the mixed flow is formed in the rainwater and sewage separate system, two sewage-rainwater mixed flow systems are formed. There are several reasons causing this problem. First, most Chinese cities develop very fast, and mostly constructed by stage, district and block. The planning lags far behind the construction speed, particularly the construction of sewage pipe system is backward, and discharge pipes are connected falsely. Second, residents are used to pour domestic sewage into the rainwater runoff collection groove. Third, the balcony is often reformed into a kitchen or washing machine and washing basin is installed in the balcony (for washing mops or so on), which discharges domestic sewage rainwater into the rainwater pipeline. According to the domestic and foreign experience, for drainage system that discharged into river channels, lakes or offshore, whether combined or separate system, the interception drainage system should be applied in the major drainage pipes or channels. Moreover, the overflow wells are set up with every certain distance along the route, and the overflow weir should be set up on the top. The major drainage pipes adopt suitable interception ratios. The ratio influences the cleanness degree of the receiving water. Ratio which is too small will result in serious pollution, and which is too large will waste the resources.

Urban drainage system in Germany has been improved constantly in the past centuries, in both of its separate and combined system. The drainage pipelines as the principal structure together with various functional ponds and affiliated apparatuses constitute a complete and efficient collection, purification, storage and utilization system of sewage, rainwater (runoff) and mixed water, and the system realizes the resource utilization of sewage and rainwater. Intercepting sewer is only set up in the combined sewer system. In view of the different forms and layouts, the intercepting sewer consists of the units in Table 1, and is often installed in the main channel. If it is placed in the side channels, purification apparatuses must be equipped.

Table 1. Units of the intercepting sewer.

\begin{tabular}{|c|c|c|c|}
\hline Drainage system & Combined system & & \\
\hline Function & Intercepting sewer (SK) & & \\
\hline Form & $\begin{array}{l}\text { Intercepting sewer with upper unloading } \\
(\mathrm{SKO})\end{array}$ & $\begin{array}{l}\text { Intercepting sewer with bottom unloading } \\
(\mathrm{SKU})\end{array}$ & $\begin{array}{l}\text { Multi-stage waterfall intercepting sewer } \\
\text { (SKK) }\end{array}$ \\
\hline Layout & Main channel (HS) (conventional) & & \\
\hline \multirow{5}{*}{ Units } & Pond overflow-weir (Bü) & Intercepting overflow-weir (Sü) & Intercepting apparatus \\
\hline & Water tank $(\mathrm{SpKa})$ & Sediment pit (SeKa) & Water tank $(\mathrm{SpKa})$ \\
\hline & Intercepting structure (DBw) & & Multi-stage waterfall structure $(\mathrm{KBw})$ \\
\hline & Unloading sewer (EK) & & - \\
\hline & Outlet structure (Abw) & & - \\
\hline
\end{tabular}

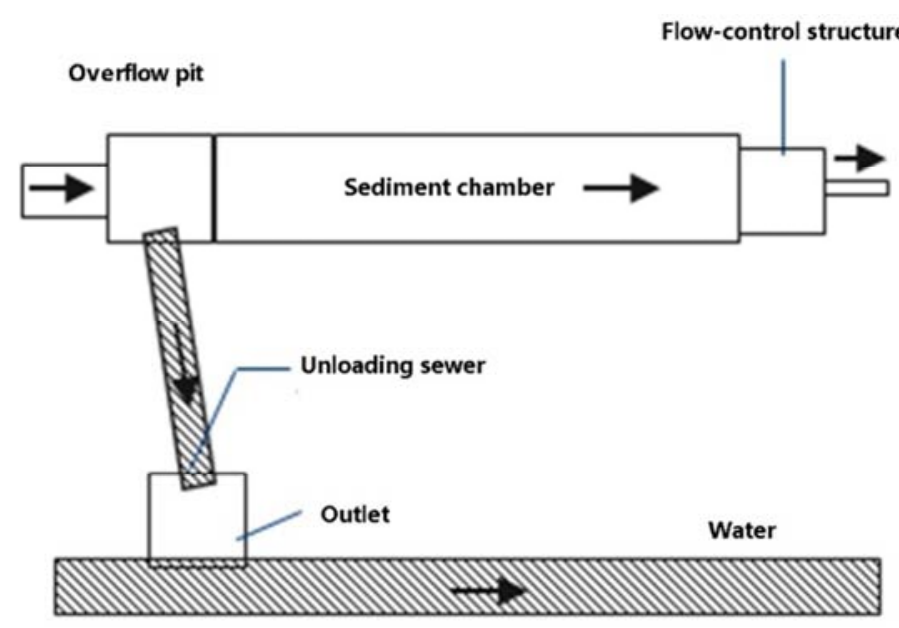

Figure 24. SKO. 


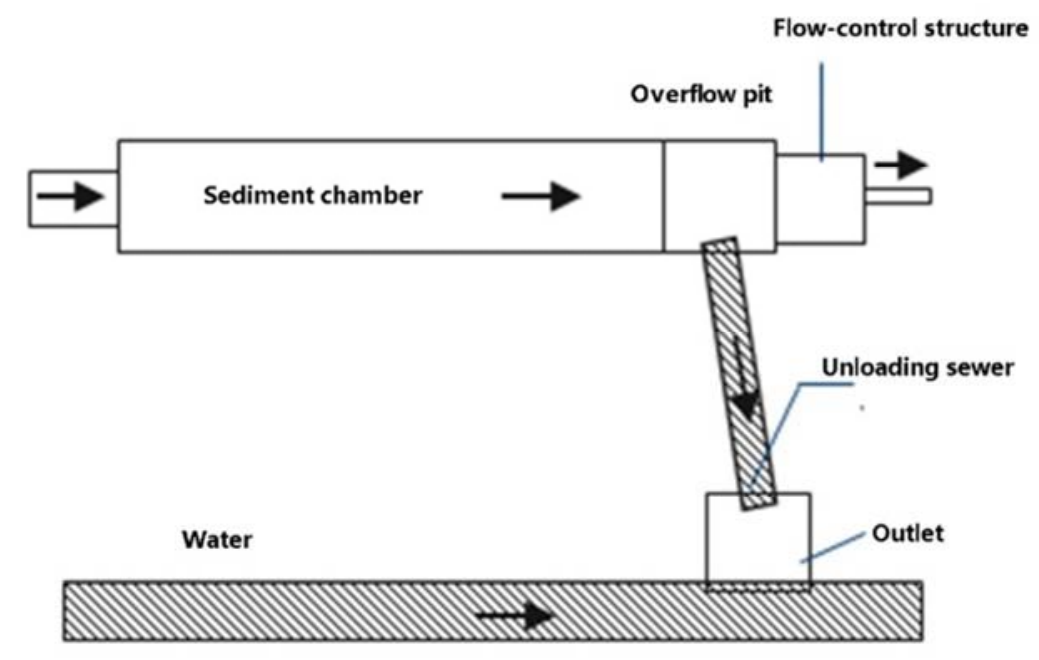

Figure 25. $S K U$.

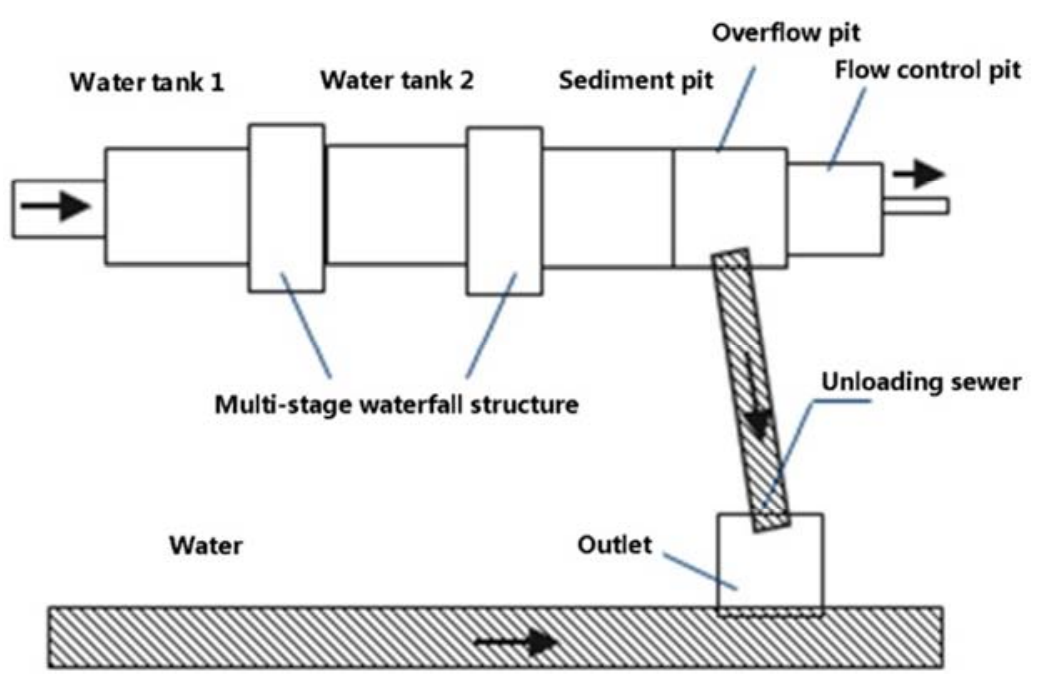

Figure 26. SKK.

vi New technologies of low-carbon sewage plant.

Main restraints for the existing sewage processing are too large occupied area and low processing efficiency, thus the technologies must be optimized by introducing the latest ones, such as the new generation of biofilm, enhanced hybrid biofilm/activated sludge process, BAF, Linpor and MBBR. The submerged biofilm-activated sludge process (SBF-AS) has already been applied in Shenzhen Caopu Sewage Plant with a processing capacity of $100000 \mathrm{t} / \mathrm{d}$.

\section{Raw sewage $\rightarrow$ Coarse screen/Lift pump station $\rightarrow$ Fine screen/paving sediment pit $\rightarrow \rightarrow$ SBF-AS Hybrid biological reaction $\operatorname{tank}(\mathrm{HRT}=6 \mathrm{~h}) \rightarrow$ Subsequent sediment tank $(\mathrm{HRT}=2 \mathrm{~h}) \rightarrow$ Effluent achieves grade $1 \mathrm{~B}$.}

In the hybrid biological reaction tank, there are both biofilm attached to the fillers and activate sludge suspended. Thus, the separation of SRT, BfRT( biofilm retention time) and HRT can be achieved. To ensure the full nitration and denitrification reaction, the retention time of biofilm can be prolonged, for example, over 15 days. In this way, nitrobacteria and denitrifying bacteria affiliated to the biofilm can grow mature. Short SRT can be applied to remove phosphorus efficiently, for example, 5 days. In addition, HRT can be greatly shortened as compared with the activated sludge, such as HRT $=4-6 \mathrm{~h}[4,5]$.

\subsection{Management and Mechanism Innovation}

\subsubsection{Responsibility Division of Government, Social Organizations and Individuals}

Construction of urban ecological civilization and improvement of water environment depends not only theory and technological innovation, but also the supporting management and mechanism innovation. The responsibilities and obligations must be divided clearly.

Government should redesign the top-level design and planning in a systematic way, focusing on the renovation and improvement of public spaces, such as strengthening the functions of parks and the management of river and lake water, 
so as to improve the quality of city environment and create environmental conditions for people's lives, and promote social equity and efficiency.

In the process of project construction, social organization should abide by relevant standards and regulations of government, strengthen management of project development and achieve the requirements of relevant indicators. Enterprises should be creative and enhance the research and implementation of maintenance and treatment technology of urban water environment.

Individuals should restrain their activities by accepting education, and enhance the consciousness of protecting and saving water resources, and contribute to the publicity.

\subsubsection{Innovation of Government Management Capacity}

In the field of ecological environment improvement and water environment management, government should play the role as a judge, making standards and regulations, controlling the approval, supervision and estimation of projects strictly.

Taking rainwater control and utilization as an example, Beijing applied the compulsory Design Standards of Rainwater Control and Utilization Projects in 2014 as a leading city of controlling and using rainwater. However, with the deepening of project review policies, rainwater control and utilization must be more scientific, flexible and efficient. The non-discretionary implementation cannot guarantee the sustainability of project. Hence, the delicacy and grid control, specific reward and punishment mechanism and flexible means of resolving conflicts will be the future direction of rainwater control and utilization. Haidian District has first applied researches and innovations of management capability in terms of rainwater control and utilization, including (a) research on the technical standards and review process of rainwater control and utilization; (b) research on the subsidy mechanism of rainwater utilization and the supplement construction mode; (c) research on the compilation of regulatory and controlled planning of rainwater.

\subsubsection{Innovation of Business Model}

i Innovation of "terminal" water service enterprise.

Through the efforts during the three periods of "five-year plan", large-scale water service enterprises have made remarkable progress and even achieved the level of developed countries in terms of technology and management capacity. It must be noticed that even China has devoted more in the policy and institutional improvement, and stressed the source control and recycling of rainwater. However, sewage, systematic and large-scale "terminal" water service technology and management enterprises are still urgently needed. Therefore, in the process of building low-carbon and ecological city, local governments must cultivate professional service companies which are integrated with planning, design, construction and maintenance, and integrate market resources to realize the scientific, orderly and high-efficiency construction, maintenance and management of urban water resource infrastructure.

ii Construction model of "technology + capital".

The core concept of "technology + capital" is to combine the technology of joint venture and the investment, i.e. in the whole life cycle of consultation planning, construction, operation and withdrawal of the urban environment improvement, as a part of the joint venture, the technical force is always carrying out the technology tracking and operation, making overall technical and sub-project effect evaluation, so as to cumulative effect of project effect, provide references for the re-investment scheme in the next stage, and save the investment to the greatest extent. In this "technology + capital" model, technology and capital are the two "gene strands" that twist and develop together, and "+" is the "hydrogen bond" that connects the "base pairs". It delivers messages and is a dynamic progress.

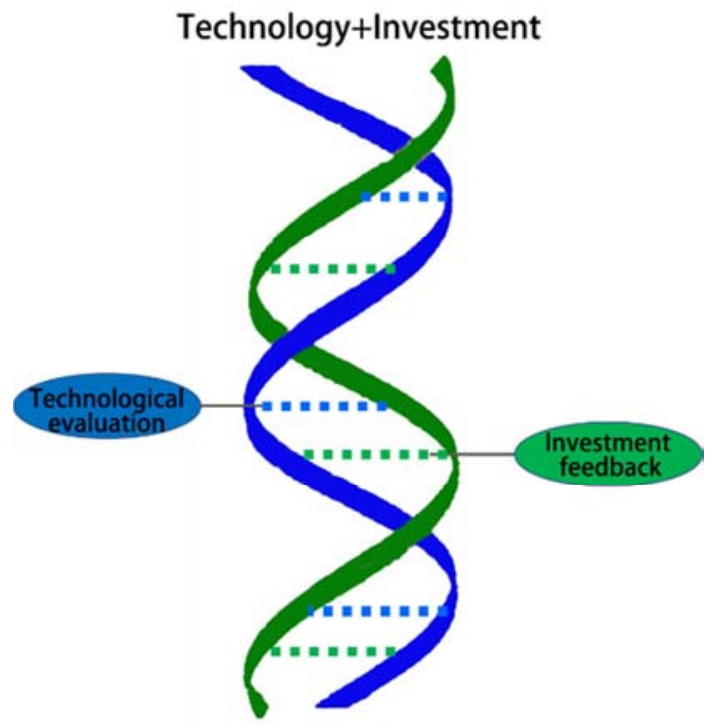

Figure 27. "Technology + capital" construction model for the improvement of urban water environment.

\subsubsection{Consciousness of Responsibility and Innovation of Propaganda and Education}

Through the innovation of tangible carriers and focusing on the actual effect, a new all-around three-dimensional pattern for the propaganda and education should be constructed. Green Flag Award is the national standard for parks and green lands in Great Britain.

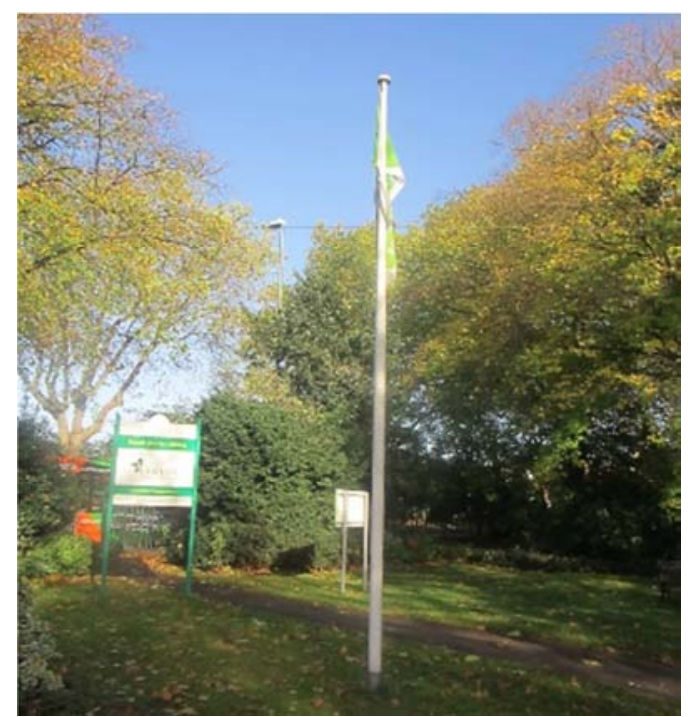




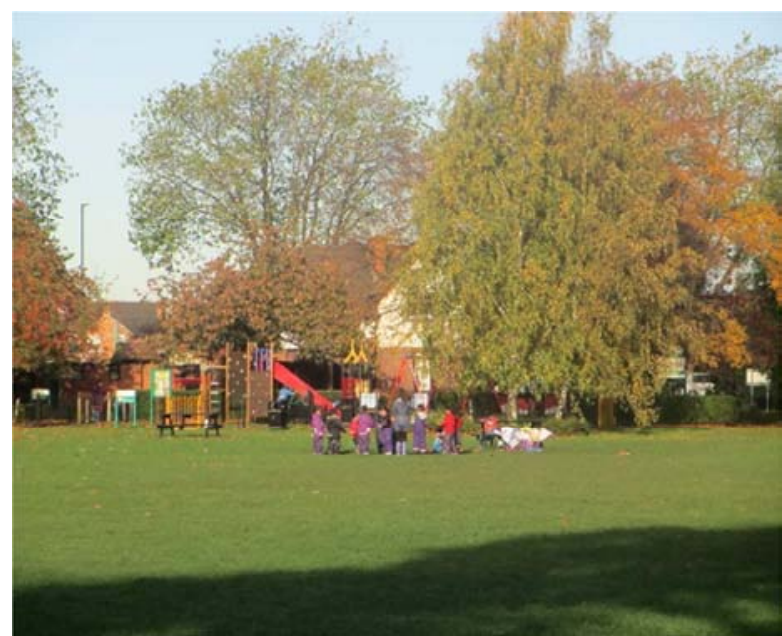

Figure 28. Green Flag Award of Leighton Park.

This award was founded in 1996 to reward the best green land nationwide. By setting the standard of outstanding for the recreational green land, the award is considered as a means of encouraging others to realize the high environment protection standards. And more importantly, winning the Green Flag Award is the best means of propaganda. Both media and the public have gradually realized that the place with a green flag must be a high-quality green land, which will surely enhance its popularity.

\section{Conclusions and Suggestions}

(1) Amend urban water environment within the systematic thinking mode.

a) The systematic thinking requires the objective and effect-oriented treatment from the perspective of the city, to achieve the goal of "no waterlogging in light rain, no flood in heavy rain, no black odorous water, relieving heat island effect", which is the concentrated reflection of urban water safety, water environment and water ecology, and also reminds us not to take the means as the objectives, or take the measures as the effects.

b) The systematic thinking requires the full consideration of all problems, including the sewage processing, rainwater collection of buildings and residential districts and so on. Rainwater and sewage separate pipelines cannot be constructed blindly, and key problems must be figured out on the basis of systematic diagnosis for the top-level planning and design. It is suggested that the urban water system planning should be promoted to the overall urban planning level, breaking through the original specialized planning of urban water supply and discharge which was not systematic or not being attached with due importance. The overall planning based on the circulation of internal and external urban waters, and surface and underground waters can constitute the overall planning layout together with urban spatial planning, energy system planning, solid garbage disposal and processing planning, smart network planning and so on.

c) The systematic thinking requires the consideration of actual conditions of the country and city. The national conditions refer to the fastest and the largest-scale urbanization in the world's history that China is experiencing as well as the predominant city diseases, the imperfect city management system, and low level of city management capacity. Actual conditions of cities refer to the differences between city scale, economic level, construction foundation and development directions. Therefore, the cities have different orientations in the amendment of urban water system. The non-discretionary implementation must be avoided. Government should make suitable technical routes for each city on the basis of sufficient investigation.

(2) Re-realize the non-point source pollution brought by rainwater, and solve the problems of rainwater flow and quality.

For all drainage systems to rivers, lakes, reservoirs and offshore, the intercepting drainage system must be applied with suitable interception ratios. In terms of drainage system, the urban drainage system and mechanism should be re-sort out with German experience in rainwater collection, transport, storage and processing.

It is not necessary to reform the drainage system in old districts into the separate system, but the interception ratio 1-2 can be taken for the main intercepting pipe (ditch) of the combined sewer system, and the processing capacity of sewage plant should be designed as 2-3 times of the sewage design flow (2-3Q). Both combined and separate drainage system should process the intercepted rainwater runoff. The source processing and utilization of both rainwater and sewage should be stressed, and it is better to separate the processing and resource utilization of rainwater and sewage.

(3) Choose rainwater and sewage technology with suitable ecological engineering sciences.

The low-carbon, energy-saving, and resource-utilization high-efficiency combined ecological processing system can be applied, such as the multi-stage strengthened eco-pond, activated sludge-biofilm biological treatment, artificial wetland, Kanerjing (an irrigation system of wells connected by underground channel), and water cellar and so on.

(4) Encourage the in-situ improvement of river water and the side flow purification technology.

The in-situ purification capacity of river water can be improved on the basis of the "concentrated + separate" treatment model. In addition, the construction of "point-line - surface" system would improve urban water environment, which includes the use of urban parks and the construction of the side flow purification project. By applying the measures above, circulation and self-purification of urban waters would be promoted, and surface water environment of the would be improved.

(5) Technological policies.

To pay the debt bought by the rapid urban sprawl, 
government, social organizations and individuals should take their own responsibilities. In the new urbanization, responsibilities of government and social organizations must be specified. Water resources can only be used and sewage discharged by giving economic compensation. More efforts should be devoted with scientific method to promote propaganda, educate and guide citizens to protect urban water environment.

\section{Acknowledgements}

The study is fund by National Key Research and Development Plan (2018YFC0406200 \& 2018YFC0704800), Youth Science and Technology Fund of China Construction Technology Group (Z2017Q05) and Technology Innovation Foundation of China Architecture Design Group (Y2017102).

\section{References}

[1] Li, W. F., Wang, Y. (2010). Characteristics of urban hardened surface structure and RS research of its scale effect. Remote Sensing for Land \& Resources, 22(1), 69-72.

[2] Hahn, H., Song, Y. H. (2006). Urban water and wastewater systems: the past, present and future. Science and Technology Review, 24(7), 5-9.

[3] Wang, B. Z., Li, J., Wang, L. (1998). Mechanism of phosphorus removal by SBR submerged biofilm system. Water Research, 32(9), 2633-2638.

[4] Wang, S. M., Wang, B. Z., Cao, X. D. et al. (2007). Reconstruction of coagulation and sedimentation system of Bujihe Wastewater Treatment Plant in Shenzhen City. China Water \& Wastewater, 23(6), 2633-2638.

[5] Wang, B. Z., Yin, W. C., Liang, S. et al. (2012). On the improvement of urban wastewater systems: the referential rainwater collection, transport, storage and processing system. Beijing: Science Press.
[6] Hills, S., Smith, A., Hardy, P., \& Birks, R. (2001). Water recycling at the millennium dome. Water Science \& Technology A Journal of the International Association on Water Pollution Research, 43(10), 287.

[7] Jr, J. G. M. (2003). Harmful algal blooms: an emerging public health problem with possible links to human stress on the environment. Annual Review of Energy \& the Environment,24(24), 367-390.

[8] Schindler, D. W. (2006). Recent advances in the understanding and management of eutrophication. Limnology \& Oceanography,51(1), 356-363.

[9] Wang, B., Wang, S., Cao, X., Jin, W., \& Dong, W. (2010). Speeding up water pollution control in Shenzhen using novel processes.

[10] Wang, S. M., Wang, B. Z., Jin, W. B., Cao, X. D., \& Tao, B. O. (2008). In-situ remediation technology for polluted water in urban river. Urban Environment \& Urban Ecology.

[11] Paffoni, C. (2001). Seine center, the new flexible colombes sewage treatment plant--from theory to practice. Water Science \& Technology A Journal of the International Association on Water Pollution Research, 44(2-3), 49.

[12] Knight, R. L., \& Kadlec, R. H. (2000). Constructed treatment wetlands - a global technology. Iwa Publishing.

[13] Gasperi, J., Laborie, B., \& Rocher, V. (2012). Treatment of combined sewer overflows by ballasted flocculation: removal study of a large broad spectrum of pollutants. Chemical Engineering Journal, 211-212(22), 293-301.

[14] Green, M. B., Martin, J. R., \& Griffin, P. (1999). Treatment of combined sewer overflows at small wastewater treatment works by constructed reed beds. Water Science \& Technology, 40(3), 357-364.

[15] Amaral, R., Ferreira, F., Galvão, A., \& Matos, J. S. (2013). Constructed wetlands for combined sewer overflow treatment in a mediterranean country, portugal. Water Science \& Technology A Journal of the International Association on Water Pollution Research, 67(12), 2739. 